\title{
Protective Effect of Nicorandil Against Contrast-Induced Nephropathy in Patients with Acute Myocardial Infarction
}

\author{
Soo Hwan Park, ${ }^{1,2}$ Myung Ho Jeong, ${ }^{1,2 *}$ In Hyae Park, ${ }^{2}$ Jin Soo Choi, ${ }^{2}$ Jung Ae Rhee, ${ }^{2}$ In Soo Kim, Keun-Ho Park, Doo Sun Sim, ${ }^{1}$ Young Joon Hong, ${ }^{1}$ Ju Han Kim, ${ }^{1}$ \\ Youngkeun Ahn, ${ }^{1}$ Jung Chaee Kang ${ }^{1}$ \\ 'The Heart Center of Chonnam National University Hospital, Gwangju, Korea; ${ }^{2}$ Department of Public Health, Chonnam National University Medical School, Gwangju, Korea
}

Received: 24 June 2015 Revised: 4 August 2015 Accepted: 10 August 2015

*Corresponding author: Myung Ho Jeong, MD, PhD, FACC FAHA, FESC, FSCAI

Principal Investigator of Korea Acute Myocardial Infarction Registry, Director of Heart Research Center Nominated by Korea Ministry of Health and Welfare, Chonnam National University Hospital, 671 Jaebongro, Dong-gu, Gwangju 61469, Korea

Tel: +82-62-220-6243

Fax: +82-62-228-7174

E-mail: myungho@chollian.net

Copyright (C) Korean Society on Thrombosis and Hemostasis. All rights reserved.
Purpose: Contrast-induced nephropathy (CIN) has resulted in significant hospital morbidity and mortality as use of contrast media (CM) for percutaneous coronary intervention (PCI) in patients with acute myocardial infarction (AMI) has been increasing. Nicorandil, a K-ATP channel opener and a nitric oxide donor, is used to treat angina pectoris. Therefore, we investigated whether the use of nicorandil would reduce the incidence of $\mathrm{CIN}$ in patients with $\mathrm{AMI}$ undergoing $\mathrm{PCl}$.

Methods: From November 2005 to August 2011, we evaluated 1,492 AMI patients with Killip class I and serum creatinine $(\mathrm{sCr})$ less than $3.0 \mathrm{mg} / \mathrm{dL}$ who underwent $\mathrm{PCl}$. The patients were divided into two groups: group I receiving nicorandil $(n=442)$ and group II not receiving nicorandil $(n=1,050)$.

Results: Among the 1,492 patients, CIN developed in $398(26.7 \%)$. There were no significant differences in baseline clinical characteristics between the two groups. The incidence of CIN also did not differ between two groups $(25.1 \%$ vs. $27.3 \%, P=0.405)$. The incidence of CIN and the increase in average percentage of $\mathrm{s} C r(\Delta \mathrm{s} C r)$ were not significantly different between the two groups $(18.2 \%$ vs. $20.4 \%, P=0.296)$. In univariate analysis, nicorandil was not an independent predictor of CIN (OR: 1.122 95\%, Cl: 0.87-1.446, $P=0.376)$.

Conclusion: The use of nicorandil did not decrease the incidence of CIN in patients with AMI undergoing PCl.

Keywords: Nicorandil, Contrast-induced nephropathy, Acute myocardial infarction, Percutaneous coronary intervention

\section{Introduction}

Contrast-induced nephropathy (CIN), also called contrast-induced acute kidney injury (AKI), is the third most common cause of hospital-acquired AKI after impaired renal perfusion and use of nephrotoxic medications. ${ }^{1} \mathrm{CIN}$ can result from intravenous or intra-arterial injections of iodine-based contrast media (CM) during enhanced computerized tomography (CT) imaging examinations or percutaneous coronary intervention (PCI). It accounts for $11-12 \%$ of all cases of in-hospital AKI and is associated with an overall in-hospital mortality rate of $6 \%{ }^{2,3}$ Risk factors of CIN include chronic kidney disease, diabetes mellitus, advanced age, congestive heart failure, nephrotoxic drug use, hypovolemia, acute hyperglycemia, increased left ventricular dysfunction, and excessive $\mathrm{CM}$ volume. The incidence of $\mathrm{CIN}$ is less than $5 \%$ in patients without risk factors but can increase to $50 \%$ among patients with multiple risk factors. ${ }^{4,5}$

Although several risk factors for CIN have been identified, the exact mechanism is not yet clear. Reducing renal perfusion due to direct effect of $\mathrm{CM}$ on the kidney lead to the development of $\mathrm{CIN}$. ${ }^{6,7}$ Therefore, many clinical trials have studied various pharmacological agents and periprocedural factors in an effort to identify successful strategies for reducing the risk. ${ }^{8-10}$ Pharmacological agents including vasodilators and antioxidants have been researched for their potential role in reducing CIN risk, a reflection of the current understanding of the pathophysiology of contrast-induced renal injury. Vasodilatory intervention with dopamine, fenoldopam, calcium channel blockers, and theophylline has been investigated, but results are inconsistent. ${ }^{11-14}$ Thus, additional large, prospective, randomized studies are required. The effect of cardioprotective agents on the kidney should be reconsidered.

Nicorandil is not only a nitric oxide donor, but also an ATP-sensitive potassium $\left(\mathrm{K}_{\mathrm{ATP}}\right)$ channel opener. ${ }^{15} \mathrm{~A}$ recent study showed that activation of the $\mathrm{K}_{\text {ATP }}$ channel prevented renal injury due to ischemia and reperfusion by reducing accumulation of reactive oxygen species (ROS) ${ }^{16}$ Nicorandil is widely used as a coronary vasodilator and is associated with better long-term prognosis in patients with stable angina and in hemodialysis patients. ${ }^{17,18}$ Nicorandil presumably acts as a pharmacological preconditioning agent and/or improves endothelial function. ${ }^{19}$ However, recent studies reported inconsistent effects of intravenous nicorandil for the prevention of $\mathrm{CIN}^{20,21}$ Therefore, we investigated the protective effect of oral nicorandil against $\mathrm{CIN}$ in patients with AMI undergoing PCI.

\section{Methods}

\section{Study population}

A retrospective analysis was performed using clinical, laboratory, and angiographic data of 1,492 AMI patients undergoing PCI within 24 hours after symptom onset between November 2005 and August 2011 at the Heart Center of Chonnam National University Hospital (Fig. 1). The patients were divided into two groups: group I receiving nicorandil $(\mathrm{n}=442)$ and group II not receiving nicorandil $(\mathrm{n}=$ 


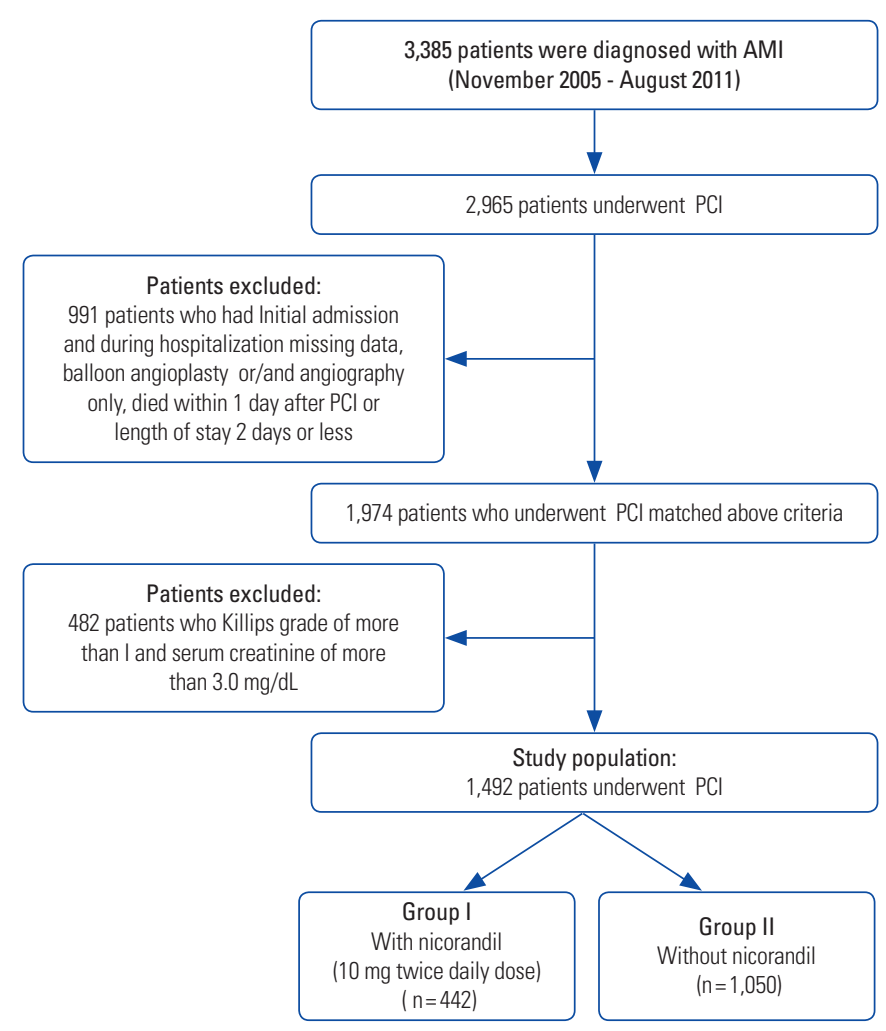

Fig. 1. The flow chart of our study.

$1,050)$. After PCI in all patients, isotonic $(0.9 \%)$ saline was administered intravenously at a rate of $1 \mathrm{~mL} / \mathrm{kg} / \mathrm{h}(0.5 \mathrm{~mL} / \mathrm{kg} / \mathrm{h}$ in cases of left ventricular ejection fraction $[\mathrm{LVEF}]<40 \%)$ for 12 hours. In both groups, isotonic $(0.9 \%)$ saline was infused using the abovementioned method. Nicorandil (Sigmart Tab. Joongwae Pharma, Seoul, Korea) $10 \mathrm{mg}$ was administered orally twice a day prior to $\mathrm{PCI}$ in the nicorandil group, while the control group did not receive nicorandil. All PCI procedures used nonionic, dimeric, iso-molar CM iodixanol (Visipaque 320; GE Healthcare AS, Oslo, Norway).

\section{Study definitions}

AMI was defined based on clinical signs or symptoms, including increased cardiac biomarkers, elevated enzyme levels (creatine kinase, creatine kinase-myocardial band isoenzyme, troponin-I, or troponin-T), and 12-lead electrocardiographic (ECG) findings. STelevation myocardial infarction (STEMI) was defined by the presence of new ST-segment elevation $>2 \mathrm{~mm}(0.2 \mathrm{mV})$ in $\geq 2$ pericardial leads, ST-segment elevation $>1 \mathrm{~mm}(0.2 \mathrm{mV})$ in $\geq 2 \mathrm{limb}$ leads, or new left bundle-branch block on the 12-lead ECG with a concomitant increase in troponin-I or $\mathrm{T} \geq 99$ th percentile up to 12 hours from the onset of symptoms. Non-ST-elevation myocardial infarction (NSTEMI) was defined by the elevation of cardiac markers (CK-MB or troponin) in the blood without the ECG change of STsegment elevation and based on a typical history of chest pain. Left ventricular ejection fraction (LVEF) was determined using two-dimensional echocardiography. High glucose level was defined as glucose level $>198 \mathrm{mg} / \mathrm{dL}(11.1 \mathrm{mmol} / \mathrm{L}) .{ }^{22} \mathrm{CIN}$ was defined as an increase $\geq 25 \%$ or $\geq 0.5 \mathrm{mg} / \mathrm{dL}$ in pre-procedure serum creatinine $(\mathrm{sCr})$ after the procedure. Serum $\mathrm{Cr}$ level was measured at baseline and daily for three days after the procedure for most of the patients.
Two daily measurements of $\mathrm{Cr}$ were performed in patients undergoing coronary angiography without PCI, as they were discharged earlier. Creatinine clearance $(\mathrm{CrCl})$ was calculated by applying the Cockcroft-Gault formula using baseline serum creatinine: $\mathrm{CrCl}=$ $([140$-age $] \times$ weight $/$ serum creatinine $\times 72)$, with female gender adjustment $\left(\mathrm{CrCl}_{\text {female }}=\mathrm{CrCl} \times 0.85\right){ }^{23}$

\section{Coronary angiography}

Coronary angiogram was analyzed with a validated quantitative coronary angiography system. Using the outer diameter of the contrast-filled catheter as the calibration standard, the minimal lumen diameter, reference diameter, and lesion length were measured in diastolic frames from orthogonal projections. The lesion morphology in coronary angiography was classified using criteria established by the American College of Cardiology (ACC)/American Heart Association (AHA) ${ }^{24}$ Perfusion was evaluated according to Thrombolysis In Myocardial Infarction (TIMI) criteria. ${ }^{25}$

\section{Study primary endpoint}

The primary end point of the study was development of CIN, defined as a $\geq 25 \%$ increase in $\mathrm{sCr}$ concentration or $\mathrm{a} \geq 0.5 \mathrm{mg} / \mathrm{dL}$ absolute increase in $\mathrm{sCr}$ from baseline within 48-72 hours after contrast exposure.

\section{Statistical analysis}

The Statistical Package for Social Sciences (SPSS) for Windows, version 19.0 (SPSS Inc., Chicago, IL, USA) was used for all analyses. Discrete variables were presented as percentages and relative frequencies and were tested with Fisher's exact test. Continuous variables were expressed as the mean value \pm standard deviation (SD), and categorical variables were described as number (percentage). Differences in baseline characteristics were compared using Student t-test for continuous variables and Pearson's Chi-square test for categorical variables.

The impact of the pretreatment of nicorandil on the incidence of CIN was evaluated using a binary logistic regression model. To more accurately clarify the impact, multivariate logistic regression analysis was performed. The covariates of high glucose level (>198 mg/ $\mathrm{dL}$ ), decreased LVEF $(<40 \%)$, old age ( $>65$ years), diabetes mellitus, hypertension, baseline $\mathrm{sCr}$ level $(>1.3 \mathrm{mg} / \mathrm{dL})$, body mass index, and gender were adjusted in this analysis. Statistical significance was defined as a $P$-value $<0.05$.

\section{Results}

Baseline clinical and laboratory characteristics

Among the total of 1,492 patients, 1,120 (75.1\%) were male, and the mean age was $68.9 \pm 12.3$ years $(59.6 \pm 12.2$ years in males, 69.0 \pm 10.3 years in females). The patients were divided into two groups, 442 patients receiving nicorandil (Group I) and 1,050 patients not receiving nicorandil (Group II). The patient baseline characteristics, including laboratory characteristics during the study, are summarized in Table 1. No significant differences were found between the groups in age, gender, body mass index, LVEF, prevalence of coronary risk factors of hypertension, diabetes, dyslipidemia, or smoking. Also, no significant differences in physical or laboratory finding were found between the two groups (Table 1).

Coronary angiographic findings and procedural characteristics No significant differences in culprit lesion, ACC/AHA lesion type, 
Table 1. Baseline clinical and laboratory characteristics

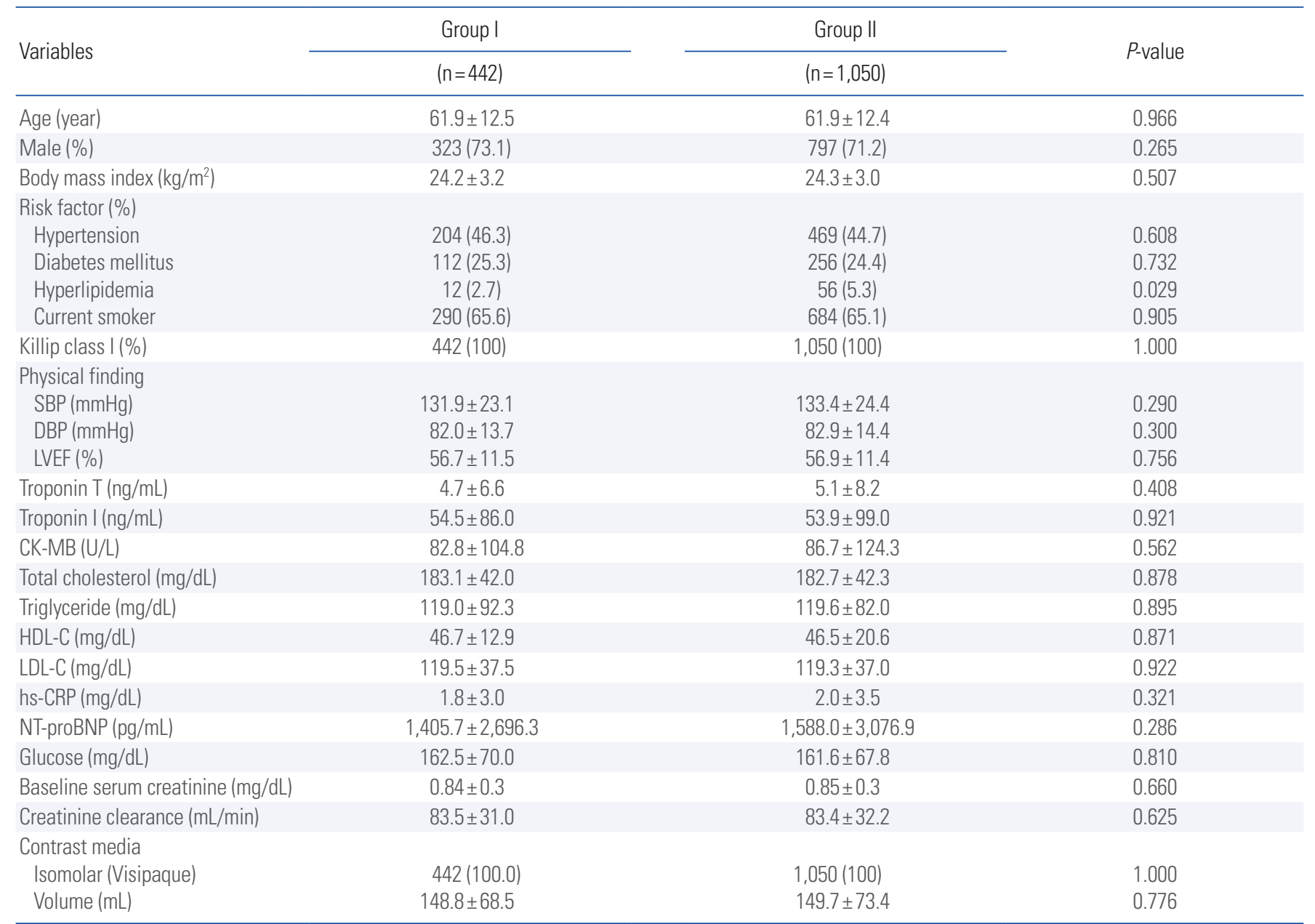

Group I: With nicorandil, Group II: Without nicorandil. Data are presented as mean \pm standard deviation for continuous variables: number (\%) for categorical variables.

SBP, Systolic blood pressure; DBP, Diastolic blood pressure; LVEF, Left ventricular ejection fraction; CK-MB fraction, Creatine kinase MB fraction; HDL-C, High-density lipoprotein-cholesterol; LDL-C, Low-density lipoprotein-cholesterol; hs-CRP, High-sensitivity C-reactive protein; NT-proBNP, N-terminal pro B-type natriuretic peptide.

Table 2. In-hospital medical treatment

\begin{tabular}{|c|c|c|c|}
\hline \multirow{2}{*}{ Variables } & Group I & Group II & \multirow{2}{*}{$P$-value } \\
\hline & $(n=442)$ & $(n=1,052)$ & \\
\hline Aspirin & 440 (99.6) & $1,041(98.4)$ & 0.039 \\
\hline Low-molecular weight heparin & $130(29.4)$ & $292(27.8)$ & 0.530 \\
\hline Beta blockers & $384(86.9)$ & $904(86.1)$ & 0.742 \\
\hline Abcixmab & $107(24.2)$ & $241(23.0)$ & 0.593 \\
\hline Calcium channel blockers & $45(10.2)$ & $103(9.8)$ & 0.850 \\
\hline Angiotensin-converting enzyme inhibitors & $394(89.1)$ & $935(89.0)$ & 1.000 \\
\hline Angiotensin receptor blockers & $88(19.9)$ & $196(18.7)$ & 0.613 \\
\hline Diuretics & $98(22.2)$ & $209(19.9)$ & 0.327 \\
\hline Statins & $329(74.4)$ & $764(72.8)$ & 0.522 \\
\hline Nitroglycerin & $433(98.0)$ & $1,026(97.7)$ & 0.849 \\
\hline
\end{tabular}

Group I: With nicorandil, Group II: Without nicorandil. Data are presented as mean \pm standard deviation for continuous variables: number (\%) for categorical variables. pre- and post-TIMI flow, or type of intervention were found between the two groups.

In-hospital medical treatment

The in-hospital medical therapy is shown in Table 2. There was no significant difference between the two groups with regard to proportion of patients receiving beta blockers, angiotensin-converting enzyme inhibitors, or statins during hospitalization.

Incidence of contrast-induced nephropathy

The primary endpoint (incidence of CIN) was similar between groups I and II (25.1\% vs. $27.3 \%, P=0.405)$. Prophylactic pretreatment with oral nicorandil did not reduce the risk of CIN. Relative changes in $\mathrm{sCr}$ from baseline to maximal $\mathrm{sCr}$ level within 48-72 hours were not significant between the wo groups (Fig. 2).

Multivariate analysis of risk factors for development of contrastinduced nephropathy

Multivariate analysis was conducted using factors determined to be 
Table 3. Multivariate analysis of risk factors for the development of contrast-induced nephropathy

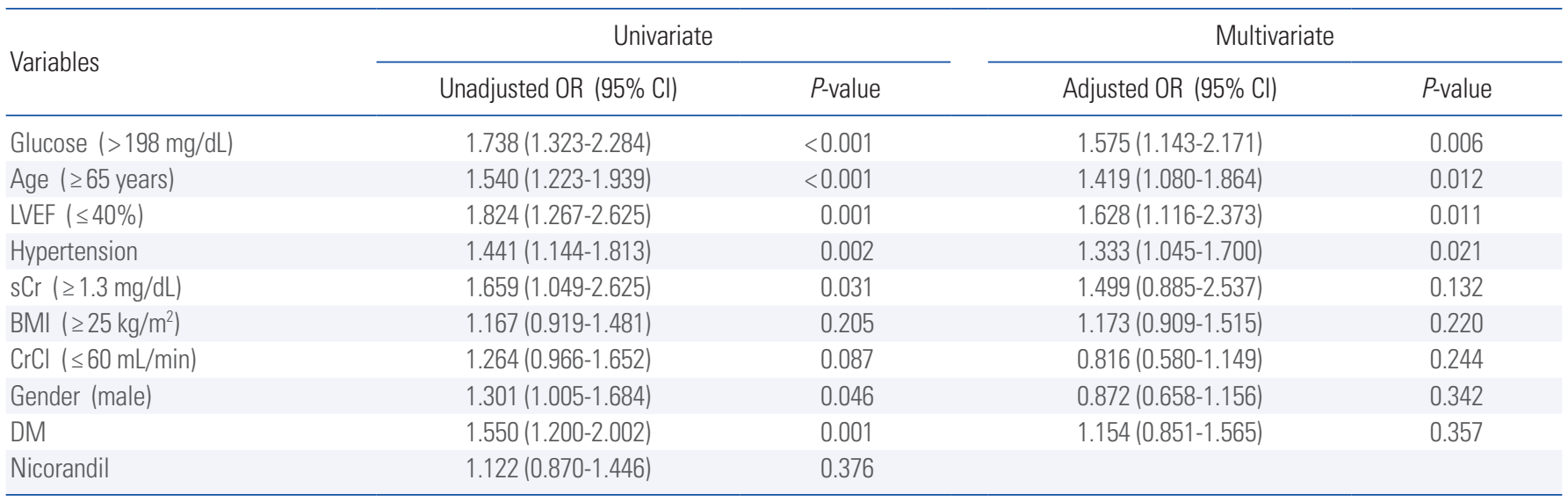

All variables found to be associated with contrast-induced nephropathy in univariate analysis with $P<0.2$ were included as covariates.

$\mathrm{Cl}$, Confidence interval; DM, Diabetes mellitus; LVEF, Left ventricular ejection fraction; sCr, Serum creatinine; CrCl, Creatinine clearance; BMI, Body mass index.

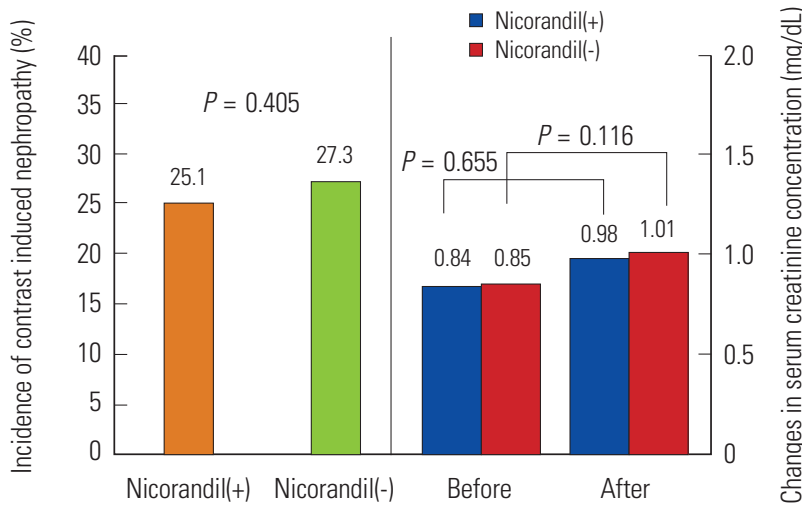

Fig. 2. Incidence of contrast-induced nephropathy in the nicorandil and control groups and changes in serum creatinine concentration before and after injection of contrast media in the nicorandil and control groups. Individual values of contrast-induced nephropathy in the nicorandil (orange) and control (green) groups are depicted. Individual changes in average serum creatinine concentration before and after injection of contrast media with nicorandil (blue) and control (red) are depicted.

significant in the univariate analysis. The predictors of CIN were higher glucose, old age, lower ejection fraction, and hypertension (Table 3).

\section{Discussion}

The hypothesis of this study is that oral nicorandil has a preventive effect on the development of CIN after AMI. However, the results of this study show that there is no significant preventive effect of nicorandil on the development of CIN.

Although several risk factors of CIN have been identified, the exact mechanism is not yet clear. Most likely, a combination of various mechanisms is responsible for development of CIN. ${ }^{26}$ Nicorandil, an $\mathrm{K}_{\mathrm{ATP}}$ channel opener and NO donor, is used in the treatment of angina and acute heart failure. ${ }^{27}$ Many studies in cardiac protection with ischemic preconditioning (IPreC) suggest that the mechanism of cardiac IPreC involves the activation and opening of
$\mathrm{K}_{\text {ATP }}$ channels. ${ }^{28,29} \mathrm{~K}_{\text {ATP }}$ channel agonists may thus have a direct effect on the underlying pathophysiological mechanism of the tissue injury after ischemia-reperfusion (I-R) injury. For example, $\mathrm{K}_{\text {ATP }}$ channel agonists are known to exert cytoprotective effects in the myocardium. ${ }^{30}$ Nicorandil has been found to prevent reperfusion injury and protect the heart against ischemic injury by promoting ischemic preconditioning. ${ }^{31}$ In addition, a recent study has shown that the $\mathrm{K}_{\text {ATP }}$ channel opener diazoxide prevents renal I-R injury. ${ }^{32}$

According to a previous study, the incidence of CIN in patients with STEMI is about $33 \% .{ }^{33}$ In the current study, the incidence of CIN was similar to that previous study (25.1\% in the nicorandil group and $27.3 \%$ in the control group). However, our study did not demonstrate a preventive effect of nicorandil on the development of CIN. Nicorandil might be effective when administered at a different dosage or frequency. The dosage was derived from the regimen for the pretreatment of patients with STEMI prior to reperfusion in clinical studies. ${ }^{34,35}$ The required dosage for the prevention of CIN may be different from the dosage used for protection against ischemia-reperfusion injury in the myocardium. It is important to minimize the quantity of CM in order to prevent CIN during the PCI procedure.

In this study, we found that acute hyperglycemia is also associated with a higher incidence of CIN in STEMI patients undergoing primary PCI. Acute hyperglycemia may have a direct negative impact on kidney function and might increase renal toxicity of contrast agents. Acute hyperglycemia suppresses flow-mediated vasodilatation, likely through increased production of oxygen-derived free radicals, and increases oxidative stress. Oxidant stress-mediated injury and renal medullary hypoxia and ischemia, due to vasoconstriction in response to contrast medium administration, have been implicated as causative factors of CIN. ${ }^{36}$

There are several limitations to this study. First, this was a singlecenter retrospective study and was not randomized or controlled. Therefore, there could have been a selection bias in enrolling patients. Second, the dosage of medication used in this study was based on STEMI preconditioning and may not proper to determine an effect of kidney protection. Third, even though multivariate regression analysis was conducted with adjustment of various basic characteristics, a randomized control study would be more appropriate in order to adjust for differences of basic characteristics. Fourth, this study might have involved potential bias due to several exclusion 
criteria. Patients with $\mathrm{sCr}$ greater than $3.0 \mathrm{mg} / \mathrm{dL}$, which is related to renal dysfunction, were excluded from this study. In addition, patients with Killip class > I, which can lead to ventricular dysfunction and myocardial infarction, were not included in this study. ${ }^{37} \mathrm{Fi}-$ nally, to correctly evaluate the incidence rate of CIN in the nicorandil group and the control group, a prospective, multi-center, randomized control trial should be conducted with adjustments for these limitations.

In conclusion, this study did not demonstrate a preventive effect of oral nicorandil treatment on the development of CIN in patients with AMI undergoing PCI.

\section{Acknowledgements}

This study was supported by grants of The Korean Health Technology R\&D Project (HI13C1527), Ministry of Health \& Welfare, Republic of Korea.

\section{Conflicts of Interest}

No authors have a relevant financial relationship to this study to disclose.

\section{References}

1. Shusterman N, Strom BL, Murray TG, Morrison G, West SL, Maislin G. Risk factors and outcome of hospital-acquired acute renal failure. Clinical epidemiologic study. Am J Med 1987;83:65-71

2. Cho JY, Jeong MH, Park SH, Kim IS, Park KH, Sim DS, et al. Effect of contrast-induced nephropathy on cardiac outcomes after use of nonionic isosmolar contrast media during coronary procedure. J Cardiol 2010; 56:300-6.

3. Kim MJ, Choi HS, Oh SH, Lee HC, Park JW, Bae EH, et al. Impact of acute kidney injury on clinical outcomes after ST elevation acute myocardial infarction. Yonsei Med J 2011;52:603-9.

4. Rihal CS, Textor SC, Grill DE, Berger PB, Ting HH, Best PJ, et al. Incidence and prognostic importance of acute renal failure after percutaneous coronary intervention. Circulation 2002;105:2259-64.

5. Mehran R, Aymong ED, Nikolsky E, Lasic Z, Iakovou I, Fahy M, et al. A simple risk score for prediction of contrast-induced nephropathy after percutaneous coronary intervention: development and initial validation. J Am Coll Cardiol 2004;44:1393-9.

6. Persson PB, Hansell P, Liss P. Pathophysiology of contrast media-induced nephropathy. Kidney Int 2005;68 14-22.

7. Wong PC, Li Z, Guo J, Zhang A. Pathophysiology of contrast-induced nephropathy. Int J Cardiol 2012;158: 186-92.

8. Merten GJ, Burgess WP, Gray LV, Holleman JH, Roush TS, Kowalchuk GJ, et al. Prevention of contrast-induced nephropathy with sodium bicarbonate: a randomized controlled trial. JAMA 2004;291:2328-34.

9. Mueller C, Buerkle G, Buettner HJ, Petersen J, Perruchoud AP, Eriksson U, et al. Prevention of contrast media-associated nephropathy: randomized comparison of 2 hydration regimens in 1620 patients undergoing coronary angioplasty. Arch Intern Med 2002;162: 329-36.

10. Stevens MA, McCullough PA, Tobin KJ, Speck JP, Westveer DC, Guido-Allen DA, et al. A prospective randomiz-ed trial of prevention measures in patients at high risk for contrast nephropathy: results of the PRINCE Study: Prevention of Radiocontrast Induced Nephropathy Clinical Evaluation. J Am Coll Cardiol 1999;33: 403-11.

11. Solomon R, Werner C, Mann D, D’Elia J, Silva P. Effects of saline, mannitol, and furosemide to prevent acute decreases in renal function induced by radiocontrast agents. N Engl J Med 1994;331:1416-20.

12. Gare M, Haviv YS, Ben-Yehuda A, Rubinger D, Bdolah-Abram T, Fuchs S, et al. The renal effect of lowdose dopamine in high-risk patients undergoing coronary angiography. J Am Coll Cardiol 1999;34:1682-8.
13. Stone GW, McCullough PA, Tumlin JA, Lepor NE, Madyoon H, Murray P, et al; CONTRAST Investigators. Fenoldopam mesylate for the prevention of contrast-induced nephropathy: a randomized controlled trial. JAMA 2003;290:2284-91

14. Huber W, Schipek C, Ilgmann K, Page M, Hennig M Wacker A, et al. Effectiveness of theophylline prophylaxis of renal impairment after coronary angiography in patients with chronic renal insufficiency. Am J Cardiol 2003;91:1157-62.

15. Kukovetz WR, Holzmann S, Braida C, Poch G. Dua mechanism of the relaxing effect of nicorandil by stimulation of cyclic GMP formation and by hyperpolarization. J Cardiovasc Pharmacol 1991;17:627-33.

16. Kimura T, Obi Y, Yasuda K, Sasaki KI, Takeda Y, Nagai $\mathrm{Y}$, et al. Effects of chronic kidney disease and post-angiographic acute kidney injury on long-term prognosis after coronary artery angiography. Nephrol Dial Transplant 2011;26:1838-46.

17. The IONA Study Group. Effect of nicorandil on coronary events in patients with stable angina: the impact of nicorandil in Angina (IONA) randomised trial. Lancet 2002;359:1269-75.

18. Nishimura M, Tokoro T, Nishida M, Hashimoto T, Kobayashi H, Imai R, et al. Oral nicorandil to reduce cardiac death after coronary revascularization in hemodialysis patients: a randomized trial. Am J Kidney Dis 2009;54:307-17.

19. Ishibashi Y, Takahashi N, Tokumaru A, Karino K, Sugamori T, Sakane T, et al. Effects of long-term nicorandil administration on endothelial function, inflammation, and oxidative stress in patients without coronary artery disease. J Cardiovasc Pharmacol 2008;51: 311-6.

20. Nawa T, Nishigaki K, Kinomura Y, Tanaka T, Yamada $\mathrm{Y}$, Kawasaki M, et al. Continuous intravenous infusion of nicorandil for 4 hours before and 24 hours after percutaneous coronary intervention protects against contrast-induced nephropathy in patients with poor renal function. Int J Cardiol 2015;195:228-34

21. Ko YG, Lee BK, Kang WC, Moon JY, Cho YH, Choi $\mathrm{SH}$, et al. Preventive effect of pretreatment with intravenous nicorandil on contrast-induced nephropathy in patients with renal dysfunction undergoing coronary angiography (PRINCIPLE Study). Yonsei Med J 2013; 54:957-64.

22. Ishihara M, Kagawa E, Inoue I, Kawagoe T, Shimatan Y, Kurisu S, et al. Impact of admission hyperglycemia and diabetes mellitus on short- and long-term mortality after acute myocardial infarction in the coronary intervention era. Am J Cardiol 2007;99:1674-9.

23. Cockcroft DW, Gault MH. Prediction of creatinine clearance from serum clearance. Nephron 1976;16:3141

24. Ellis SG, Guetta V, Miller D, Whitlow PL, Topol EJ. Coronary morphologic and clinical determinants of procedural outcome with angioplasty for multivessel coronary disease: implications for patient selection Multivessel Angioplasty Prognosis Study Group. Circulation 1990;82:1193-202.

25. Manginas A, Gatzov P, Chasikidis C, Voudris V, Pavlides G, Cokkinos DV. Estimation of coronary flow reserve using the Thrombolysis in Myocardial Infarction (TIMI) frame count method. Am J Cardiol 1999;83: 1562-5.

26. Thomsen HS, Morcos SK. Contrast media and the kidney: European Society of Urogenital Radiology (ESUR) guidelines. Br J Radiol 2003;76:513-8.

27. Taira N. Nicorandil as a hybrid between nitrates and potassium channel activators. Am J Cardiol 1989;63: $18 \mathrm{~J}-24 \mathrm{~J}$.

28. Auchampach JA, Gross GJ. Adenosine A1 receptors, KATP channels, and ischemic preconditioning in dogs Am J Physiol 1993;264:1321-36.

29. Van Winkle DM, Chien GL, Wolff RA, Soifer BE, Kuzume K, Davis RF. Cardioprotection provided by adenosine receptor activation is abolished by blockade of the KATP channel. Am J Physiol 1994;266:829-39.

30. Zager RA, Johnson AC, Lund S, Hanson SY, Abrass CK. Levosimendan protects against experimental endotoxemic acute renal failure. Am J Physiol Renal Physiol 2006;290:1453-62.

31. Sato T, Sasaki N, O'Rourke B, Marbán E. Nicorandil, a potent cardioprotective agent, acts by opening mitochondrial ATP-dependent potassium channels. J Am Coll Cardiol 2000;35:514-8.

32. Sun Z, Zhang X, Ito K, Li Y, Montgomery RA, Tachibana $\mathrm{S}$, et al. Amelioration of oxidative mitochondrial DNA damage and deletion after renal ischemic injury by the KATP channel opener diazoxide. Am J Physio Renal Physiol 2008;294:491-8.

33. Marenzi G, Assanelli E, Marana I, Lauri G, Campodonico J, Grazi M, et al. N-acetylcysteine and contrast-induced nephropathy in primary angioplasty. N Engl J Med 2006; 354:2773-82.

34. Miki T, Seino S. Roles of KATP channels as metabolic sensors in acute metabolic changes. J Mol Cell Cardiol 2005;38:917-25.

35. Ishii H, Ichimiya $\mathrm{S}$, Kanashiro $\mathrm{M}$, Amano T, Imai $\mathrm{K}$, Murohara T, et al. Impact of a single intravenous administration of nicorandil before reperfusion in patients with ST-segment-elevation myocardial infarction. Circulation 2005; $112: 1284-8$

36. Marenzi G, De Metrio M, Rubino M, Lauri G, Cavallero A, Assanelli E, et al. Acute hyperglycemia and contrast-induced nephropathy in primary percutaneous coronary intervention. Am Heart J 2010;160:1170-7.

37. Khot UN, Jia G, Moliterno DJ, Moliterno DJ, Lincoff $\mathrm{AM}$, Khot MB, et al. Prognostic importance of physical examination for heart failure in non-ST-elevation acute coronary syndromes: the enduring value of Killip classification. JAMA 2003:290:2174-81. 